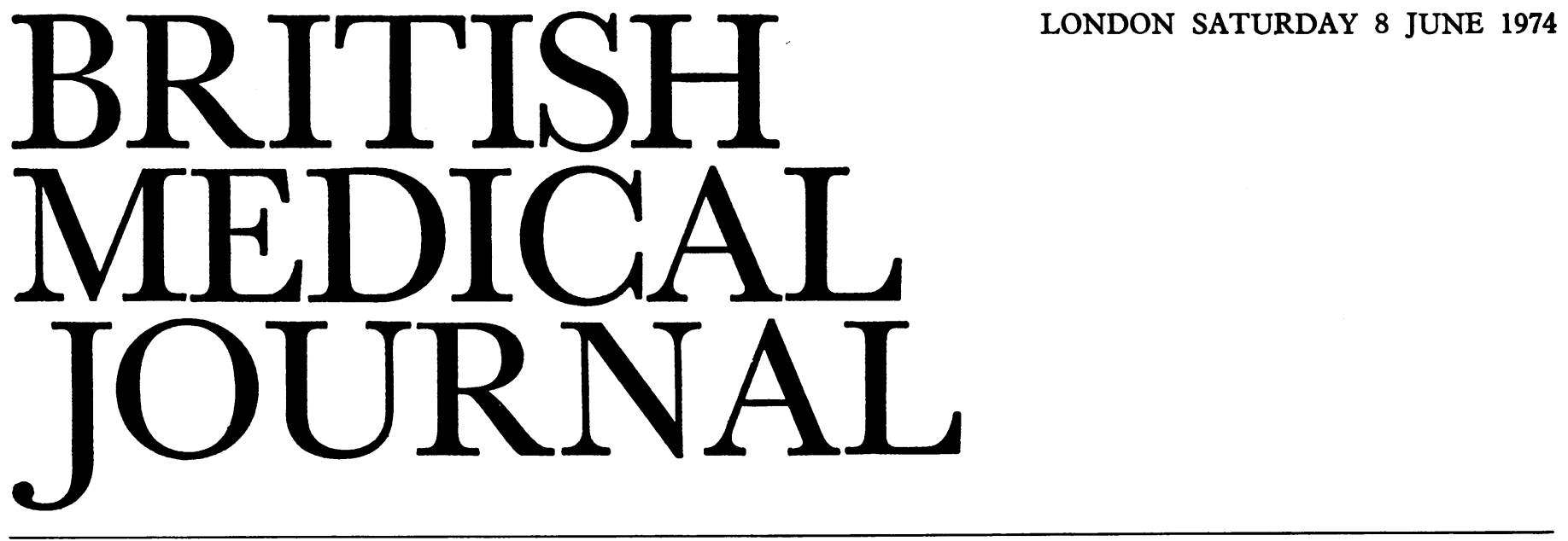

\title{
Achalasia of the Cardia
}

Achalasia implies inability of the lower oesophageal sphincter to relax after a swallow; the reflex which normally prepares the sphincter for the oncoming bolus of food is interrupted. The tone of the sphincter is said to be normal; cardiospasm is not present. Peristalsis is also abolished throughout the entire length of the oesophagus, to be replaced in some patients by non-propulsive "tertiary" contractions. This classical view has recently been challenged by more refined motility studies which show that the tone of the sphincter is in fact increased and does partially relax on swallowing. ${ }^{1}$ Since relaxation is incomplete, the passage of food remains obstructed, and stasis occurs. The oesophagus then behaves rather like a hopper; passage through the sphincter depends on gravity and the height of the column of stagnant food.

The aetiology of achalasia is unknown. Transient achalasia may follow vagotomy, which suggests that damage to the nerve supply of the oesophagus is crucial. In 1930, A. F. Hurst and G. W. Rake noted lesions in the ganglion cells of the myenteric plexus, and C. P. Symonds remarked that this resembled infection by a neurotropic virus. ${ }^{2}$ Since then the primary lesion has been placed more proximally, with abnormalities described in the dorsal nucleus of the vagus and in the vagus nerve itself. $^{3-5}$ The myenteric plexus is certainly abnormal in structure, ${ }^{5}$ though a recent pharmacological study suggested that the ganglia and postganglionic fibres are functionally intact. ${ }^{6}$ It therefore seems that both vagus nerve and myenteric plexus may be implicated, but that the structure and function of either or both may be partially preserved. Histological studies are compatible with a virus infection, ${ }^{5}$ but achalasia has also been attributed to invasion of the myenteric plexus by carcinoma cells? (though it is possible that the carcinoma followed the achalasia). Recently the hormone gastrin has been found to increase the tone of the cardiac sphincter. ${ }^{8}$ Patients with achalasia are extremely sensitive to normal circulating amounts of gastrin, which increases sphincter tone to high levels. ${ }^{9}$ This is not, however, the primary cause of achalasia, but a secondary effect of oesophageal denervation; the cholinergic drug methacholine has a similarly enhanced effect on the body of the oesophagus when injected as a diagnostic test.

Achalasia occurs in patients of any age and sex. The classical story is one of gradual onset of progressive painless dysphagia for both solids and liquids. It may be described as a fullness after meals, often located at the xiphisternum and relieved by drinking water; emotional stress aggravates the symptom. Loss of weight is unusual. Vomiting is rare; it is really regurgitation, and the vomitus lacks the usual sour taste of gastric contents. Belching, a frequent feature of most oesophageal disorders, is also uncommon since the oesophagus is effectively blocked by stagnant food.

Pain in the chest is said to be rare, but many patients do remember attacks of severe spontaneous retrosternal pain during the years preceding the onset of dysphagia, which may have been due to intense repetitive tertiary contractions in the body of the oesophagus. Occasionally these pains continue into the later stages of the disease. The pain may radiate widely, may occur during both day and night, and can last for several hours. ${ }^{10}$ It is not provoked by food or drink but may be relieved by drinking a little cold water. This pain should not be confused with the bursting sensation that results from eating too quickly, the discomfort due to impaction of food at the sphincter, or the heartburn which may follow attempts at treatment. American authors have recently rediscovered this symptom and use the presence of pain as the basis for the diagnosis of a syndrome which they call "vigorous achalasia."11 12

Pulmonary complications due to spill-over are common and may be the presenting feature. Patients complain of wheezing, coughing, and choking sensations, especially at night. Sometimes pneumonia or lung abscess is the first sign of achalasia, and patients often die of acute or chronic lung disease. Recently, P. E. Giustra and his colleagues ${ }^{13}$ described two patients who presented with acute stridor due to compression of the trachea by the enormous oesophagus. One died of massive aspiration, but the enlarged oesophagus of the second was recognized on a routine chest radiograph and successfully decompressed. Another complication is carcinoma of the oesophagus, which usually spreads silently in the dilated organ and so presents late. It is thought to result from the stasis in lumen and occurs at higher levels of the oesophagus and at a younger age than usual. ${ }^{14} 15$

Achalasia may often be diagnosed from the history, but physical examination is unrewarding. Chest radiography may reveal a megaoesophagus with a fluid level. Barium swallow shows absence of peristalsis and varying degrees of dilatation and food retention, with a tapering cone at the level of the sphincter which differentiates achalasia from carcinoma. The gastric air bubble may be absent, but only after the oesophageal lumen has been permanently blocked by food. Radiographs should be taken in the supine position to prevent gravity from aiding oesophageal emptying in the early stages. Motility studies are diagnostic but are not routinely available. 
Oesophagoscopy should be performed to exclude carcinoma; the ease with which the instrument passes the sphincter belies the radiological appearances and indirectly supports the diagnosis.

Treatment is still controversial. The tone of the cardiac sphincter may be decreased by mechanical rupture of its fibres (forceful dilatation) or cardiomyotomy (Heller's operation). Both procedures may give rise to after-effects, both have partisan supporters, and satisfactory controlled trials are lacking. In the United Kingdom the emphasis has been almost exclusively on cardiomyotomy in recent years, but adequate careful dilatation under radiological control may still give good results in up to $77 \%$ of patients, even after more than three years. ${ }^{16} 17$ Either form of treatment should be performed early, before the oesophagus becomes permanently enlarged, and even then lung disease may not be prevented.

1 Cohen, S., and Lipshutz, W., Gastroenterology, 1971, 61, 814.

2 Hurst, A. F., and Rake, G. W., Quarterly fournal of Medicine, 1930, 23, 491

${ }^{3}$ Cassella, R. R., Brown, A. L., Sayre, G. P., and Ellis, F. H., Annals of Surgery, 1964, 160, 474 .

4 Cassella, R. R., Ellis, F. H., and Brown, A. L., American fournal of Pathology, 1965, 46, 279

5 Smith, B., Gut, 1970, 11, 388.

6 Cohen, S., Fisher, R., and Tuch, A., Gut, 1972, 13, 556

7 Kolodny, M., Schrader, Z. R., Rubin, W., Huchman, R., and Sleisenger, M. H., Annals of Internal Medicine, 1968, 69, 569 .

8 Cohen, S., and Lipshutz, W., Fournal of Clinical Investigation, 1971, 50 449.

- Cohen, S., Lipshutz, W., and Hughes, W., fournal of Clinical Investigation, 1971, 50, 1241.

10 Edwards, D. A. W., American fournal of Digestive Diseases, 1968, 13, 340.

1 Sanderson, D. R., Ellis, F. H., and Schlegel, J. F., Diseases of the Chest, $1967,52,508$.

12 Bondi, J. L. Godwin, D. H., and Garrett, J. M., American fournal of Gastroenterology, 1972, 58, 145.

13 Giustra, P. E., Killoran, P. J., and Wasgatt, W. N., American fournal of Gastroenterology, $1973,60,160$

14 Lortat-Jacob, J. L., Richard, C. A., Fekete, F., and Testart, J., Surgery, $1969,66,969$

15 Pierce, W. S., MacVaugh, H., and Johnson, J., fournal of Thoracic and Cardiovascular Surgery, $1970,59,335$.

16 Bennett, J. R., and Hendrix, T. R., Modern Treatment, 1970, 7, 1217

17 Vantrappen, G., Hellemans, J., Deloof, W., Valembois, P., and Vandenbroucke, J., Gut, 1971, 12, 268 .

\section{Private Practice in Teaching Hospitals}

Two subjects of current interest in the U.S.A. are methods of funding medical schools and, as a linked topic, how the academic clinician might allocate his time. The alternatives were recently discussed by three eminent American administrators. ${ }^{1}$ The choices lie between the strict full-time system, where the doctor is a salaried employee of the institution in which he works; goegraphical full-time appointments that allow the practitioner to supplement his income from limited private practice, performed within the confines of the employing institution; and group partnership private practice in which individuals put their fees into a common pool from which they each draw a salary up to a previously agreed ceiling, the residue then going to the medical school. This last scheme enables the rich departments in the medical faculty to support those where the private practice income is smaller or absent. Though the differences in the finance of health care on the other side of the Atlantic invalidate direct comparisons with this country, there were a number of points considered in the symposium that are relevant to the British situation.

Perhaps the most interesting factual findings come from a survey $^{2}$ of the activities of American academic clinicians. It seems that non-surgeons who are strictly full-time spend considerably fewer hours attending patients than their geographical full-time colleagues and have very many fewer patients to care for. Indeed their clinical practice seems so restricted that one wonders wheth 2 r such a limited exposure to clinical medicine allows them to remain competent to practise and teach. On the other hand, as one might imagine, strict full-timers spend much more of their time doing research and (as will be known ${ }^{3}$ to followers of the British scene) in travelling. Geographical full-time workers evidently do their share of teaching and are considerably more successful, for reasons unspecified, in obtaining research grants. They also draw a larger salary-so it is hardly surprising that more geographical full-timers were satisfied with their jobs than the strict full-timers, surgeons or non-surgeons.

In Britain, the clinical staff of university hospitals is made up of N.H.S. employees, who may be whole or part-time, and those whose salary is paid by the university. The whole-time N.H.S. consultant may be just as academic as the professorial head of a clinical department, while some of those holding university posts may do as much clinical work as their N.H.S. colleagues. It is dangerous to generalize on the work of the staff of the British teaching hospitals, as patterns vary across the country, but in some institutions the Flexnerian view of the professorial department still prevails. Staff, money, and space in the hospital and medical school, the argument runs, should go to the professorial unit since there they will be used most efficiently. This results in gross imbalance between university departments and N.H.S. groups. In other teaching hospitals there is a happy symbiosis between the university and N.H.S. staff, where each has a service commitment coupled to a clinical and research interest in one or more areas. The professorial unit has the prime responsibility for the organization of undergraduate and in some instances postgraduate teaching. In this system there is little difference between the activities of university and Health Service employees, provided the latter work on a full-time contract. There is, however, still considerable variation in the role of the part-timer. The doctor who has a busy, private practice and at the same time carries out worthwhile research is still a rarity. Where there is a choice, cash usually wins.

There is a trend among physicians in teaching hospitals towards acceptance of a full-time contract, mainly owing to their having developed in the course of training a visceral urge to continue in clinical investigation. It is also partly a reflection of the relatively poor monetary reward that accrues to all but a few and of the widely held, but possibly erroneous, feeling that a great deal of time spent in private practice is devoted to caring for the trivial. Of the other clinical branches of the profession, academic or full-time appointments in surgery and gynaecology are unpopular because of the very considerable financial rewards available from private practice. Furthermore, there are still some financial sanctions imposed on those working for the university and paid out of university funds. Increases in doctors' salaries come to university staff a month or two after they have reached their health service confrères-no insignificant penalty when interest rates are running at approximately $15 \%$. University employees are still not given the very lirge removal allowances available to health service staff, and those in training are not eligible for the extra duty allowances payable to N.H.S. training grades. If the universities wish to compete in the market for the best clinical brains then they must be prepared to pay their employees the same as the N.H.S.

There are other anomalies: the professor with an honorary N.H.S. appointment may see private patients and charge them 